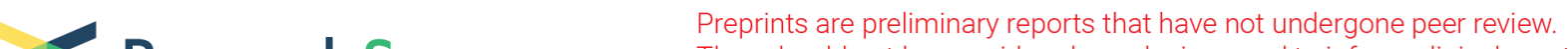 Research Square \\ Cat1 Regulate ROS Metabolism and Microsclerotia Formation in the Dimorphic Fungus Nomuraea Rileyi
}

\section{Yu Su}

School of life sciences Chongqing University

\section{Xuyi Wang}

Southeast Chongqing Academy of Agricultural Sciences

\section{Haiying Yu}

General station of forest and grassland pest management, National forestry and grassland administration

\section{Yuanli Luo}

Southeast Chongqing academy of agricultural sciences

\section{Bingfeng Zhao}

Southeast chongqing academy of agricultural sciences

\section{Huan Jiang}

Southeast chongqing academy of agricultural sciences

\section{Guiting Tang}

Southeast chongqing academy of agricultural sciences

\section{Yong Zhang}

Southeast chongqing academy of agricultural sciences

\section{Chaojun Wu}

Southeast chongqing academy of agricultural sciences

\section{Youping Yin ( $\sim$ ypy128@vip.sina.com )}

Chongqing UniversityChongqing UniversityChongqing UniversityChongqing UniversityChongqing University https://orcid.org/0000-0001-5587-5726

\section{Research Article}

Keywords: Nomuraea rileyi, Catalases, Agrobacterium tumefaciens-mediated transformation (ATMT), Split-marker, ROS metabolism, Microsclerotium

Posted Date: September 23rd, 2021

DOI: https://doi.org/10.21203/rs.3.rs-918054/v1 
License: (c) (i) This work is licensed under a Creative Commons Attribution 4.0 International License. Read Full License 


\section{Abstract}

Catalases are the most important enzymes in the metabolism of reactive oxygen species (ROS), as they convert hydrogen peroxide $\left(\mathrm{H}_{2} \mathrm{O}_{2}\right)$ into water and molecular oxygen. They are also involved in virulence, and in oxidative, heat, hyperosmotic stress and UV-B radiation responses in some entomopathogenic fungi. In this study, the Cat1 gene from Nomuraea riley $i$ was cloned and its function was studied by gene deletion. The $\mathrm{NrCat1}$ deletion mutant $(\Delta \mathrm{NrCat1}$ ) was generated using the split-marker method. No significant differences in colony growth or dimorphic switching of $\Delta \mathrm{NrCat1}$ were observed under regular culture conditions, whereas oxidative stress inhibited colony growth and the yeast-hyphal transition. In contrast, there was no significant difference in tolerance to hyperosmotic stress between $\triangle \mathrm{NrCat1}$ and wild type (WT) strains. In the $\Delta \mathrm{NrCat1}$ strain, microsclerotia (MS) formation time of the $\Delta \mathrm{NrCat1}$ was delayed, and MS size was less uniform than in the WT. MS yield was decreased by $76 \%$ in the $\Delta \mathrm{NrCat1}$ strain compared to the WT strain. Furthermore, virulence was attenuated in the $\triangle \mathrm{NrCat1}$ strain. Gene expression analysis showed that $\mathrm{NrCat2}$, NrCat4, and $\mathrm{NrAox}$ are up-regulated to compensate for $\mathrm{NrCat1}$ deletion. Thus, the $\mathrm{NrCat}$ gene in $\mathrm{N}$. rileyi appears to be involved in essential functions, including $\mathrm{H}_{2} \mathrm{O}_{2}$ metabolism, MS formation, and virulence.

\section{Highlights}

An $N$. rileyi NrCat1 deletion mutant was generated by using the split-marker method.

$\Delta$ NrCat1 were observed sensitive to $\mathrm{H}_{2} \mathrm{O}_{2}$.

$\Delta \mathrm{NrCat1}$ defects in microsclerotia (MS) formation.

Virulence was attenuated in the $\Delta \mathrm{NrCat1}$ strain.

NrCat2, NrCat4, and NrAox are compensate for NrCat1 deletion.

\section{Introduction}

Nomuraea rileyi is an important entomopathogenic fungus which infects lepidopterous pests, in particular Noctuidae spp., and it has potential in insect biocontrol. However, the sporulation of $N$. rileyi requires specific conditions, including light stimulation, and a maltose carbon source, which limits its potential for commercialization. To solve this problem, microsclerotia (MS) of $N$. rileyi induced by liquid amended media (AM) (Yin et al. 2012) have been used successfully as a substitute for conidia in insect biocontrol.

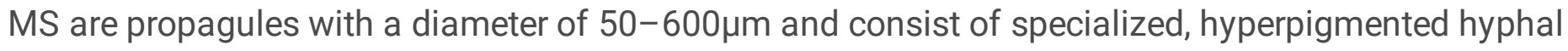
aggregations. Compared with $N$. rileyi conidia, MS have a higher production efficiency and persistence longer in the field. Other entomopathogenic fungi, such as Metarhizium brunneum (Jackson et al. 2016) 
and Metarhizium anisopliae (Jackson and Jaronski 2008) also produce MS and they have been used in insect biocontrol.

In filamentous fungi, genetic and biochemical investigations have indicated that reactive oxygen species (ROS) play a critical role in various aspects of cell physiology, cellular differentiation, cell signaling, and pathogen defense (Kawasaki and Aguirre, 2001). Previously, comparative transcriptome analysis of $N$. rileyi was performed to study the moleculare mechanisms of MS development. This study showed that oxidative stress is a key factor in MS development (Song et al. 2013). Multiple N. rileyi genes involved in MS development have been identified. For example, small GTPase, RacA, Cdc42 and their regulatory factors Cdc24 and Bem1, regulate MS formation through the control of ROS generation (Jiang et al. 2014; Song et al. 2016). Similarly, the NADH: flavin oxidoreductase/NADH oxidase gene (Nox) and alternative oxidase (Aox) genes are involved in MS formation through regulation of intracellular $\mathrm{H}_{2} \mathrm{O}_{2}$ concentrations (Liu et al. 2014; Zhou et al. 2015). Defects in the transmembrane sensor genes Sho1 and $\operatorname{Sin} 1$ (Song et al. 2015), and deletion of two MAPK genes, Hog1 and S/t2, also inhibit MS formation (Song et al. 2016).

Catalases are the most important enzymes in ROS metabolism. In the ROS metabolism system, superoxide dismutases (SODs) and catalases convert superoxide and $\mathrm{H}_{2} \mathrm{O}_{2}$ into water and molecular oxygen (Polidoros et al. 2001; Alscher et al. 2002; Schouten et al. 2002; Kwok et al. 2004). Previously, catalases were shown to play an important adaptive role to the environmental stress. In Beauveria bassiana, five catalase genes, CatA, CatB, CatP, CatC and CatD were shown to be involved in the regulation of virulence and tolerance to oxidative stress, high temperatures and UV-B radiation (Wang et al. 2013). Overexpression of the Cat1 gene in $M$. anisopliae, increases resistance to exogenous $\mathrm{H}_{2} \mathrm{O}_{2}$, reduces germination time, and increase virulence (Hernandea et al. 2010). In contrast, Neurospora crassa Cat1 mutants exhibit defects in the survival of conidia under oxidative and light-induced stress (Wang et al. 2007), whereas Cat3 mutants exhibit defects in growth and differentiation. In Aspergillus oryzae, the Cat $B$ gene may play a role in detoxification of oxidative stress (Hisada et al. 2005). In the phytopathogenic fungus Claviceps purpurea, catalase has been shown to be involved in suppression of the host defense system (Garre et al. 1998). Additionally, peroxisomal catalases may be involved in insect hydrocarbon catabolism (Pedrini et al. 2006). Together these results show that fungal catalase genes are important for detoxification, cellular differentiation, and catabolism. However, there have been no reports on the involvement of catalase genes in MS formation.

In this study, we isolated genomic DNA and CDNA of the $N$. rileyi Cat1 gene and investigated its role in the formation of MS by gene disruption.

\section{Materials And Methods}

\subsection{Strains and growth conditions}

The N. rileyi strain Nr01 was stored in the Engineering Research Center of Fungal Insecticides, Chongqing, China. The fungus was grown on solid SMAY media consisting of $40 \mathrm{~g} \mathrm{~L}^{-1}$ maltose, $15 \mathrm{~g} \mathrm{~L}^{-1}$ yeast extract 
power, and $10 \mathrm{~g} \mathrm{~L}^{-1}$ peptone. Blastospore were collected at early time points. Conidia were collected after spore production by scraping the colonies, suspending in sterile $0.05 \%$ Tween- 80 solution and filtrering through three layers of lens wiping paper. Then, the blastospores were suspended in sterile phosphate buffered saline (PBS) and washed three times in PBS with centrifugation.

N. rileyi spores were incubated in liquid AM (Yin et al. 2012) at $28^{\circ} \mathrm{C}$ with shaking at $250 \mathrm{rpm}$.

Escherichia coli DH5a cells were used to propagate and maintain plasmids following standard procedures. Agrobacterium tumefaciens AGL-1 laboratory stocks were used to transform N. rileyi. The wild type (WT) A. tumefaciens AGL-1 was cultured in YEB media with $50 \mu \mathrm{g} \mathrm{mL}^{-1}$ streptomycin. For growth of plasmid-carrying $A$. tumefaciens $50 \mu \mathrm{g} \mathrm{mL}^{-1}$ kanamycin was added to the media. The plasmids pPZP-Split-marker-A and pPZP-Split-marker-B-Gus were used to generate $\triangle \mathrm{NrCat1}$ mutant.

\subsection{Cloning the NrCat1 gene of $N$. rileyi}

The partial NrCat1sequence was acquired from transcriptome data (Song et al. 2013). The full cDNA and genomic sequences were obtained using fusion primer and nested integrated PCR (FPNI-PCR) (Wang et al. 2011). The amino acid sequence was deduced using BlastX searches in GenBank. Phylogenetic trees were generated using MEGA 5.0 software.

\subsection{Generation of $\Delta \mathrm{NrCat1}$ mutants}

The flanking regions of NrCat1 were obtained from genomic DNA by FPNI-PCR (Wang et al. 2011). pPZPSplit-marker-A-NrCat1 and pPZP-Split-marker-B-Gus-NrCat1 were expanded in E. coli DH5a prior to being transformed into the A. tumefaciens. A. tumefaciens-mediated transformation of WT N. rileyi with pPZPSplit-marker-A-NrCat1 and pPZP-Split-marker-B-Gus-NrCat1 was performed as described by Shao et al (2015).

Putative transformants were screened on SMAY supplemented with $450 \mu \mathrm{g} \mathrm{ml}^{-1}$ hygromycin-B.

Preliminary screening of transformants were carried out using a $\beta$-glucuronidase (GUS) assay, and GUSnegative transformants was further confirmed by PCR with the primers listed in Table S1. Gene deletion mutants were further assessed by Southern blot analysis according to the manufacturer's protocol (Roche, Mannheim, Germany).

\subsection{Gene expression patterns of $N$. rileyi WT and $\Delta$ NrCat1 strains during MS development}

The transcription levels of $\mathrm{NrCat1}, \mathrm{NrCat2}$, NrCat4, and $\mathrm{NrAox}$, were investigated by real-time quantitative PCR (RT-qPCR) at different time points during MS development.

WT and $\triangle$ NrCat1 strains were inoculated into flanks containing $100 \mathrm{~mL}$ of liquid $A M$ with $0.5 \mathrm{~mL}$ of conidia suspension $\left(1 \times 10^{8} \mathrm{sp} \mathrm{mL}{ }^{-1}\right)$. The flasks were incubated with shaking at $28^{\circ} \mathrm{C}, 250 \mathrm{rpm}$ for $1.5-7$ days. Samples were collected at the following time points: germinating spores (1.5-2 days), yeast like cells (2.5-3 days), MS initiation (SI) and hyphal period (3.5-4 days), MS formation (4.5-5 days), MS 
maturation (5.5-6 days), and secondary mycelial growth (6.5-7 days). After centrifugation and two washes with sterile distilled water, total RNA was isolated using TRIzolß reagent (Invitrogen, Carlsbad, CA, USA). First strand cDNA was synthesized using SuperScript II Reverse Transcriptase (Invitrogen, USA) according to the manufacturer's instructions. RT-qPCR was performed using SYBR® Green II mix (Takara, Shiga, Japan) according to the manufacturer's protocol. Primers used to measure expression levels of NrCat1, NrCat2, NrCat4, and NrAox, are described in Table S1. Each sample was prepared in triplicate and each reaction was carried out three times. NrTef and NrTub genes were used as reference genes.

\subsection{Phenotypic analysis of the $\Delta$ NrCat1 strains}

\subsection{1 $\mathrm{H}_{2} \mathrm{O}_{2}$ sensitivity of WT and $\Delta$ NrCat1 strains}

The filter paper method was used to assess sensitivity to $\mathrm{H}_{2} \mathrm{O}_{2}$ sensitivity in WT and $\Delta \mathrm{NrCat1}$ strains. Conidial suspensions $\left(1 \times 10^{6} \mathrm{sp} \mathrm{mL}{ }^{-1}\right)$ of WT and $\Delta N r C a t 1$ strains were spread onto plates, and a 4-mm filter paper containing 800,1600 , or $3200 \mathrm{mM} \mathrm{H}_{2} \mathrm{O}_{2}$ was placed on the center of each plate. Conidial suspensions $\left(1 \times 10^{7}, 1 \times 10^{6}\right.$, and $\left.1 \times 10^{5} \mathrm{sp} \mathrm{mL} \mathrm{mL}^{-1}\right)$ of WT and $\triangle \mathrm{NrCat1}$ were pipetted onto SMAY plates and SMAY with $2 \mathrm{mM} \mathrm{H}_{2} \mathrm{O}_{2}$ for colony morphology evaluation. All the treatments incubated at $25^{\circ} \mathrm{C}$.

\subsubsection{Hyperosmolarity tolerance of WT and $\Delta$ NrCat1 strains}

Tolerance of $\mathrm{WT}$ and $\triangle \mathrm{NrCat1}$ strains to $\mathrm{NaCl}, \mathrm{KCl}, \mathrm{LiCl}$, and sorbitol was tested on solid SMAY media. Conidial suspensions $\left(1 \times 10^{8} \mathrm{sp} \mathrm{mL}{ }^{-1}\right)$ were inoculated onto the centers of the plates and incubated at $25^{\circ} \mathrm{C}$. Colony diameter was measured every 3 days after 6 days of incubation. For the evaluation colony morphology three concentrations of conidial suspensions $\left(1 \times 10^{7}, 1 \times 10^{6}\right.$, and $\left.1 \times 10^{5} \mathrm{sp} \mathrm{mL}^{-1}\right)$ were pipetted onto plates.

\subsection{MS formation of $\Delta \mathrm{NrCat1}$}

MS formation capacities of WT and $\triangle N r C a t 1$ strains was examined by inoculating $0.5 \mathrm{~mL}$ of conidia $\left(1 \times 10^{8} \mathrm{sp} \mathrm{mL}^{-1}\right)$ into $100 \mathrm{~mL}$ of liquid $\mathrm{AM}$ and incubating at $28^{\circ} \mathrm{C}$ with shaking at $250 \mathrm{rpm}$ for 3.5-6 days. MS yield and morphologies were observed using a microscope.

\subsection{Virulence assays}

Virulence of WT and $\Delta \mathrm{NrCat1}$ strains was assessed by immersing third-instar larvae of Prodenia litura into five concentrations of conidial suspensions $\left(5 \times 10^{6} \mathrm{sp} \mathrm{mL}^{-1}, 1 \times 10^{7} \mathrm{sp} \mathrm{mL}{ }^{-1}, 2.5 \times 10^{7} \mathrm{sp} \mathrm{mL}^{-1}\right.$, $5 \times 10^{7} \mathrm{sp} \mathrm{mL} \mathrm{m}^{-1}$, and $1 \times 10^{8} \mathrm{sp} \mathrm{mL}{ }^{-1}$ ). A $0.05 \%$ Tween-80 solution without fungus was used as a control. Insects were reared in incubators at $26^{\circ} \mathrm{C}$ after treatment. Mortality was recorded every 24 hours and the $50 \%$ mortality (LC50) value was calculated using the minimum squares method. Each treatment was repeated three times using 15 larvae per replicate.

\section{Results}




\subsection{Isolation and characterization of Cat1 from N. rileyi}

Using the expressed sequence tag (EST) of the Cat1 gene isolated from the transcriptome library of $N$. rileyi, the full-length sequence of the NrCat1 gene obtained by FPNI-PCR was found to be $2561 \mathrm{bp}$ encoding 716amino acid residues. The protein had a calculated molecular weight of $79.085 \mathrm{KDa}$ and an isoelectric point (PI) of 5.92 (http://expasy.org/tools/protparam.html).

A phylogenetic tree of $\mathrm{NrCat1}$ constructed using MEGA5.0 software showed that $\mathrm{NrCat1}$ is closely related to Metarhizium spp. (Fig. 1).

\subsection{Time-specific expression patterns of NrCat1during MS development}

The expression level of NrCat1 during MS development was analyzed by RT-qPCR. Results showed that $\mathrm{NrCat1}$ was expressed at all developmental stages and picked (12-fold) during the SI and hyphal period (84 hours). NrCat1 was also significantly up-regulated (6-fold) during the secondary mycelial growth period (156 hours) compared with the germinating spore period (48 hours). These results indicate that NrCat1 may be involved in hyphal growth and MS formation (Fig. 2A).

\section{3 $\mathrm{H}_{2} \mathrm{O}_{2}$ sensitivity $\Delta$ NrCat1}

To further assess the role of $\mathrm{NrCat1}$ in MS development, an $\mathrm{N}$. rileyi NrCat1 deletion mutant was generated by using the split-marker method (in print).

WT and $\triangle N r C a t 1$ conidia were grown on SMAY plates supplemented with $2 \mathrm{mM} \mathrm{H}_{2} \mathrm{O}_{2}$ for 7 days at $25^{\circ} \mathrm{C}$. No differences in morphology were observed between WT and $\triangle \mathrm{NrCat1}$ colonies. However, the dimorphic switch was delayed by approximately 1 and 2 days in the $\triangle N r C a t 1$ strain grown on SMAY plates supplemented with $2 \mathrm{mM} \mathrm{H}_{2} \mathrm{O}_{2}$ compared with the WT strain (Fig. $3 \mathrm{~A}$ ). In $\mathrm{H}_{2} \mathrm{O}_{2}$ inhibition tests, the $\triangle N r C a t 1$ inhibition zone was bigger than that of WT. The size of the inhibition zones of $\Delta N r C a t 1$ grown at $\mathrm{H}_{2} \mathrm{O}_{2}$ concentrations of 800,1600 and $3200 \mathrm{mM}$ were $1.7,1.6$, and 1.2 times larger, respectively, compared with WT strains grown at the same concentrations (Fig. 3B). Variance analysis showed that the diameter of the inhibition zones of $\Delta \mathrm{NrCat1}$ grown at $\mathrm{H}_{2} \mathrm{O}_{2}$ concentrations of 800 and $1600 \mathrm{mM}$ were significantly different from WT strains $(P<0.01)$. These results indicate that $\mathrm{NrCat1}$ is involved in $\mathrm{H}_{2} \mathrm{O}_{2}$ metabolism.

\section{4 hyperosmolarity tolerance of $\mathrm{NrCat1}$}

WT and $\triangle \mathrm{NrCat1}$ conidia were grown on SMAY plates supplemented with $1 \mathrm{M} \mathrm{NaCl}, 1 \mathrm{M} \mathrm{KCl}, 0.04 \mathrm{M} \mathrm{LiCl}$ and $1 \mathrm{M}$ sorbitol for 18 days at $25^{\circ} \mathrm{C}$. The growth rate of both WT and $\Delta \mathrm{NrCat1}$ strains was inhibited by the hyperosmolarity but colony morphologies and hyphal extension rates were not different between the two strains $(P>0.5)$ (Fig. 4). 


\subsection{MS formation of $\Delta \mathrm{NrCat1}$}

WT and $\triangle N r C a t 1$ conidia were inoculated into liquid $A M$ and cultures were grown with shaking. MS formation of WT strains was observed after 3.5-4 days, whereas MS formation of $\Delta \mathrm{NrCat1}$ was delayed until 4.5-5 days. Additionally, the fermentation broth of $\Delta N r C a t 1$ strain was less viscous and had a paler

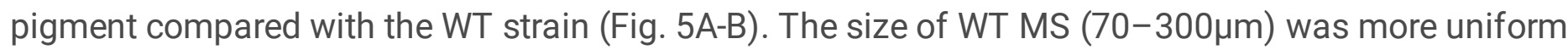
than $\Delta$ NrCat1 MS $(50-1500 \mu \mathrm{m})$ (data not shown). Furthermore, the MS yield of $\Delta \mathrm{NrCat1}$ was reduced by approximately $76 \%$ compared with the WT (Fig. 5C).

\subsection{NrCat2, NrCat4, and NrAox are up-regulated to compensate for NrCat1 deletion during MS formation}

Expression analysis of NrCat2, NrCat4 and NrAox during MS development was carried out in the WT and $\triangle N r C a t 1$ strain. Results showed that in the WT strain transcription levels of both catalase genes were high during the SI period. Transcription levels of the NrCat4 gene were high during the spore germinating and secondary mycelial growth periods. Transcription levels of NrAox were high during the germinating spore and SI periods (Fig. 2B-D).

Transcription levels of the NrCat2 gene were higher in $\Delta \mathrm{NrCat1}$ than in WT. At 108 hours, compensation was greatest with $\mathrm{NrCat2}$ (approximately 17-fold), during the SI period (Fig. 2B). Interestingly, NrCat4 and NrAox exhibited a complicated expression pattern. Before the SI period NrCat4 and NrAox expression was similar between WT and $\triangle N r C a t 1$. However, from the SI period to the MS maturation period transcription levels of $\mathrm{NrCat} 4$ and $\mathrm{NrAox}$ were higher in $\Delta \mathrm{NrCat1}$ than in WT. The highest compensation occurred at 96 hours, when NrCat4 was up-regulated by 3.5-fold (Fig. 2C) and NrAox was up-regulated by 4.2 -fold (Fig. 2C) compared with WT. These results indicate that in N. rileyi NrCat1, NrCat2, NrCat4 and NrAox may share similar functions during MS formation.

\subsection{NrCat1 influences $\mathbf{N}$. rileyi virulence}

In virulence assays using $P$. litura larvae and muscardine cadavers, no difference in morphology between WT and $\Delta$ NrCat 1 was observed (Fig. 6). However, the virulence of $N r C a t 1$ was decreased by $64 \%$

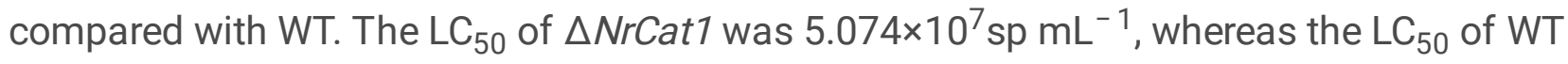
was $1.81 \times 10^{7} \mathrm{sp} \mathrm{mL}^{-1}$.

\section{Discussion}

In the present study, we identified and isolated an N. rileyi catalase gene of that is up-regulated during MS formation. Based on sequence identity, this gene encodes a protein related to the monofunctional catalases, of the entomopathogenic fungi M. anisopliae (MaCat1 FN641683.1) and B. bassiana (BbCatB JX050139.1), and the phytopathogenic fungi Magnaporte grisea (MgCatB MG06442). 
Previous studies have demonstrated that catalases are involved in virulence and responses to oxidative, heat, and hyperosmotic stress, and UV-B radiation in M. anisopliae, B. bassiana and M. grisea (Giles et al. 2006; Skamnioti et al. 2006; Wang et al. 2013). In this study, no significant differences in colony growth or dimorphic switching from yeast to hyphae on solid media were observed in $\Delta \mathrm{NrCat1}$ mutants compared with the WT strain. However, under oxidative stress both colony growth and dimorphic switching was inhibited in $\Delta N r C a t 1$ compared with the WT strain. Additionally, a significant difference in the tolerance of conidia to $\mathrm{H}_{2} \mathrm{O}_{2}$ was observed (Fig. 3). These findings are consistent with the reported role of Cat1 in ROS metabolism in M. anisopliae (Hernandez et al. 2010), B. bassiana (Wang et al. 2013) and M. grisea (Skamnioti et al. 2007). Moreover, deletion of the NrCat1 homolog MgCatB in M. grisea causes accelerated hyphal growth but also results in paler pigmentation, lower biomass, more fragile conidia and appressoria, poor sporulation and impaired melanization (Skamnioti et al. 2007), but in $B$. bassiana and $N$. rileyi the Cat1 mutants were not observed in these phenotype changes (Wang et al. 2013).

This study also reproted a significant up-regulation of $\mathrm{N}$. rileyi NrCat1 during MS development and secondary mycelial growth. In contrast, NrCat1 deletion caused both a reduction in the quantity of MS production by approximately $76 \%$ compared with the WT strain and irregular MS morphology. These results indicate that Cat1 affect ROS metabolism and MS formation in N. rileyi.

Oxidative stress has been demonstrated as an inducing factor in sclerotium differentiation (Georgiou and Petropoulou 2002; Georgiou and Zees 2002; Patsoukis and Georgiou 2007a, b). Proper concentrations of $\mathrm{H}_{2} \mathrm{O}_{2}$ will promote the formation of $\mathrm{MS}$ and high concentrations of $\mathrm{H}_{2} \mathrm{O}_{2}$ will inhibit the MS formation (Liu et al. 2015). Gene expression analysis of NrCat1, NrCat2 and NrCat4 during MS development of WT $N$. rileyi showed that these three catalase genes are up-regulated during the SI period, suggesting that concentrations of $\mathrm{H}_{2} \mathrm{O}_{2}$ are higher during MS formation. $\triangle \mathrm{NrCat1}$ mutants exhibited defects in both MS proliferation and morphology. Moreover, in $\triangle \mathrm{NrCat1}$, NrCat4 expression levels were higher during MS formation (form 84-144 hours) compared with the WT strain. Additionally, NrCat2 expression levels were higher throughout the entire MS development process (from 36-168 hours). These results indicate that $\mathrm{NrCat} 2$ and $\mathrm{NrCat} 4$ are up-regulated to compensate for $\mathrm{NrCat1}$ deletion during MS formation. Similar results have been described in $B$. bassiana where $B b C a t B$ deletion was compensated by up-regulation of $B b C a t C$ under oxidative stress conditions (Wang et al. 2013). However, in M. grisea, MgCatB mutants do not exhibit overexpression of other catalase or catalase-related antioxidant genes (Skamnioti et al. 2007). These results indicate that the function of $\mathrm{NrCat1}$ is similar to that of $\mathrm{BbCatB}$.

Interestingly, in $\triangle \mathrm{NrCat1}$ mutants another ROS metabolism gene, NrAox, was over-expressed during MS formation (from 84-144 hours) (Fig. 2B). Previous studies have indicated that Aox is involved in metabolism of ROS generated by energy production and metabolism in fungi (Hattori et al. 2008; Helmerhorst et al. 2005; Ruy et al. 2006). In N. rileyi, defects in NrAox leads to reductions the disability in ROS metabolism and MS formation (Zhou et al. 2015). In the current study, gene expression analysis showed that NrAox was up-regulated to compensate for NrCat1 deletion. These results suggest that Aox may function in a similar way to catalases by regulating ROS metabolism during MS formation. 
The catalase gene has been reported to be an essential virulence factor in entomogenous fungi (Feng et al. 1994; Hernandez et al. 2010; Wang et al. 2013) and phytopathogenic fungi (Skamnioti et al. 2007). In the present study, deletion of $\mathrm{NrCat1}$ caused a significant decrease in virulence, which is consistent with previous studies. However, whether $\mathrm{NrCat} 2$ or $\mathrm{NrCat} 4$ are involved in virulence requires further research.

In conclusion, deletion of the NrCat1 gene affected ROS metabolism and MS development in N. rileyi. $\mathrm{NrCat} 2$ and $\mathrm{NrCat} 4$ were up-regulated to compensate for the absence of NrCat1. We also demonstrated that the NrAox gene was up-regulated to compensate for NrCat1 deletion in N.rileyi, which has not previously been reported.

\section{Declarations}

\section{Acknowledgement}

Project supported by Natural Science Foundation of China (Grant. No. 31570073)

•Funding Project supported by Natural Science Foundation of China (Grant. No. 31570073).

-Conflict of interest The authors declare that they have no conflict of interest.

-Code availability None.

-Availability of data and materials The datasets and materials used in the current study are available from the corresponding author on reasonable request.

\section{References}

Alscher RG, Erturk N, Heath LS (2002) Role of superoxide dismutases (SODs) in controlling oxidative stress in plants. J Exp Bot 53:1331-1341. https://doi.org/10.1093/jexbot/53.372.1331

Garre V, Tenberge KB, Eising R (1998) Secretion of a fungal extracellular catalase by Claviceps purpurea during infection of rye: putative role in pathogenicity and suppression of host defense. Phytopathology 88:744-753. https://doi.org/10.1094/PHYT0.1998.88.8.744

Georgiou CD, Petropoulou KP (2002) The role of ascorbic acid role in the differentiation of sclerotia in sclerotinia minor. Mycopathologia 1542:71-77. https://doi.org/10.1023/A:1015542916751

Georgiou CD, Zees A (2002) Lipofuscins and sclerotial differentiation in phytopathogenic fungi. Mycopathologia 1534:203-208. https://doi.org/10.1023/A:1014988419357

Giles SS, Stajich JE, Nichols C et al (2006) The Cryptococcus neoformans catalase gene family and its role in antioxidant defense. Eukaryot Cell 59:1447-1459. https://doi.org/10.1128/EC.00098-06 
Goble TA, Gardescu S, Fisher JJ et al (2016) Conidial production, persistence and pathogenicity of hydromulch formulations of Metarhizium brunneum, f52 microsclerotia under forest conditions. Biol Control 95:83-93. https://doi.org/10.1016/j.biocontrol.2016.01.003

Hattori T, Honda Y, Kino K et al (2008) Expression of alternative oxidase gene (aox1) at the stage of single-cell conidium in citric acid-producing Aspergillus niger. Journal of Bioscience Bioengineering 1051:55-57. https://doi.org/10.1263/jbb.105.55

Helmerhorst EJ, Stan M, Murphy MP et al (2005) The concomitant expression and availability of conventional and alternative, cyanide-insensitive, respiratory pathways in Candida albicans. Mitochondrion 53:200-211. https://doi.org/10.1016/j.mito.2005.04.001

Hernandez CEM, Guerrero IEP, Solis ES et al (2010) Catalase overexpression reduces the germination time and increases the pathogenicity of the fungus Metarhizium anisopliae. Appl Microbiol Biotechnol 873:1033-1044. https://doi.org/10.1007/s00253-010-2517-3

Hisada H, Hata Y, Kawato A et al (2005) Cloning and expression analysis of two catalase genes from Aspergillus oryzae. Journal of Bioscience Bioengineering 99:562-568.

https://doi.org/10.1263/jbb.99.562

Jaronski ST, Jackson MA (2008) Efficacy of Metarhizium anisopliae microsclerotial granules. Biocontrol Science Technology 18:849-863. https://doi.org/10.1080/09583150802381144

Jiang SS, Yin YP, Song ZY et al (2014) Raca and $c d c 42$ regulate polarized growth and microsclerotium formation in the dimorphic fungus Nomuraea rileyi. Res Microbiol 165(3):233-242. https://doi.org/233242. 10.1016/j.resmic.2014.03.003

Kawasaki L, Aguirre J (2001). Multiple catalase genes are differentially regulated in Aspergillus nidulans. Journal of Bacteriology 183: 1434-1440. https://doi.org/10.1128/JB.183.4.1434-1440.2001

Kwok LY, Schlüter D, Clayton C et al (2004) The antioxidant system in Toxoplasma gondii and the role of cytosolic catalase in defense against oxidative injury. Mol Microbiol 51:47-61.

https://doi.org/10.1111/j.1365-2958.2005.04829.x

Liu JJ, Yin YP, Song ZY et al (2014) NADH: flavin oxidoreductase/NADH oxidase and ROS regulate microsclerotium development in Nomuraea rileyi. World J Microbiol Biotechnol 307:1927-1935. https://doi.org/10.1007/s11274-014-1610-7

Pedrini N, Juárez MP, Crespo $R$ et al (2006). Clues on the role of Beauveria bassiana catalases in alkane degradation events. Mycologia 98: 528-534. https://doi.org/10.1007/s11274-014-1610-7

Polidoros AN, Mylona PV, Scandalios JG (2001). Transgenic tobacco plants expressing the maize Cat2 gene have altered catalase levels that affect plant-pathogen interactions and resistance to oxidative stress. Transgenic research 10: 555-569. https://doi.org/10.1023/A:1013027920444 
Ruy F, Vercesi AE, Kowaltowski AJ (2006) Inhibition of specific electron transport pathways leads to oxidative stress and decreased Candida albicans proliferation. Journal of Bioenergetics Biomembranes 382:129-135. https://doi.org/10.1007/s10863-006-9012-7

Schouten A, Tenberge KB, Vermeer $\mathrm{J}$ et al (2002) Functional analysis of an extracellular catalase of Botrytis cinerea. Molecular Plant Pathology 3:227-238. https://doi.org/10.1046/j.13643703.2002.00114.x

Shao CW, Yin YP, Qi ZR et al (2015) Agrobacterium tumefaciens-mediated transformation of the entomopathogenic fungus Nomuraea rileyi. Fungal Genetics Biology 83: 19-25. https://doi.org/ 10.1016/j.fgb.2015.08.002

Skamnioti P, Henderson C, Zhang Z al (2007) A novel role for catalase B in the maintenance of fungal cell-wall integrity during host invasion in the rice blast fungus Magnaporthe grisea. Molecular plantmicrobe interactions 205:568-580. https://doi.org/10.1094/MPMI-20-5-0568

Song ZY, Shen L, Yin YP et al (2015) Role of two Nomuraea rileyi transmembrane sensors sho1p and $\sin 1 \mathrm{p}$ in adaptation to stress due to changing culture conditions during microsclerotia development. World J Microbiol Biotechnol 313:477-485. https://doi.org/10.1007/s11274-015-1801-x

Song ZY, Yin YP, Jiang SS et al (2013) Comparative transcriptome analysis of microsclerotia development in Nomuraea rileyi. BMC Genom 141:411. https://doi.org/10.1186/1471-2164-14-411

Song ZY, Zhong Q, Yin YP et al (2016) The high osmotic response and cell wall integrity pathways cooperate to regulate morphology, microsclerotia development, and virulence in Metarhizium rileyi. Scientific Reports 6:38765. https://doi.org/10.1038/srep38765

Wang NY, Yoshida Y, Hasunuma K (2007) Loss of Catalase-1 (Cat-1) results in decreased conidial viability enhanced by exposure to light in Neurospora crassa. Mol Genet Genomics 277:13-22. https://doi.org/10.1007/s00438-006-0170-4

Wang Z, Ye SF, Li JJ et al (2011) Fusion primer and nested integrated PCR FPNI-PCR.: a new highefficiency strategy for rapid chromosome walking or flanking sequence cloning. BMC Biotechnol 111: https://doi.org/109. 10.1186/1472-6750-11-109

Wang ZL, Zhang LB, Ying SH et al (2013) Catalases play differentiated roles in the adaptation of a fungal entomopathogen to environmental stresses. Environ Microbiol 152:409-418. https://doi.org/10.1111/j.1462-2920.2012.02848.x

Yin YP, Shan H, Song ZY et al (2012) Microsclerotia artificial inductions of Nomuraea rileyi CQNrr01. China Agriculture Science 4523: 4801-4807 In Chinese. https://doi.org/10.3864/j.issn.05781752.2012.23.006 
Zhou GL, Song ZY, Yin YP et al (2015) Involvement of alternative oxidase in the regulation of hypha growth and microsclerotia formation in Nomuraea rileyi CQNr01. World J Microbiol Biotechnol 31:13431352. https://doi.org/10.1007/s11274-015-1877-3

\section{Figures}

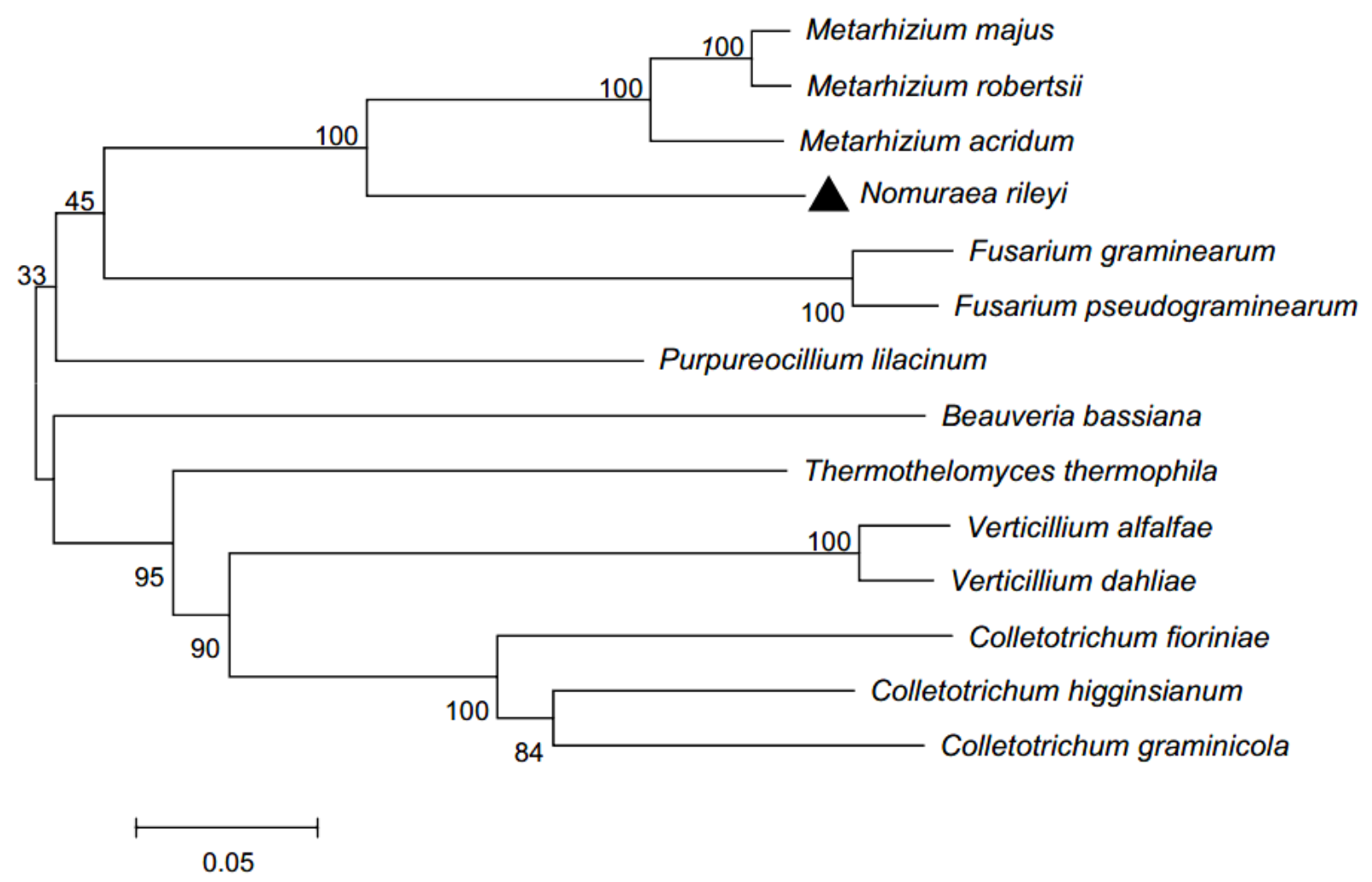

\section{Figure 1}

Phylogenetic tree inferred from Cat1 DNA sequence alignment using the neighbor-joining $(\mathrm{NJ})$ method in MEGA5.0 software. The aligned sequences of Cat1 are from Metarhizium acridum CQMa 102 (GenBank accession No. XM_007811861.1), Metarhizium majus ARSEF 297 (XM_014726471.1), Purpureocillium lilacinum (XM_018322662.1), Fusarium graminearum PH-1 (XM_011328072.1), Fusarium pseudograminearum CS3096 (XM_009262196.1), Thermothelomyces thermophila ATCC 42464 ( XM_003662984.1), Colletotrichum higginsianum IMI 349063 (XM_018298034.1), Colletotrichum fioriniae PJ7 (XM_007598278.1), Colletotrichum graminicola M1.001(XM_008092892.1), Verticillium alfalfae VaMs.102, (XM_003001071.1), Verticillium dahliae VdLs.17 (XM_009658953.1), Metarhizium robertsii ARSEF 23 (XM_007823877.1), and Beauveria bassiana (JX050139.1) 

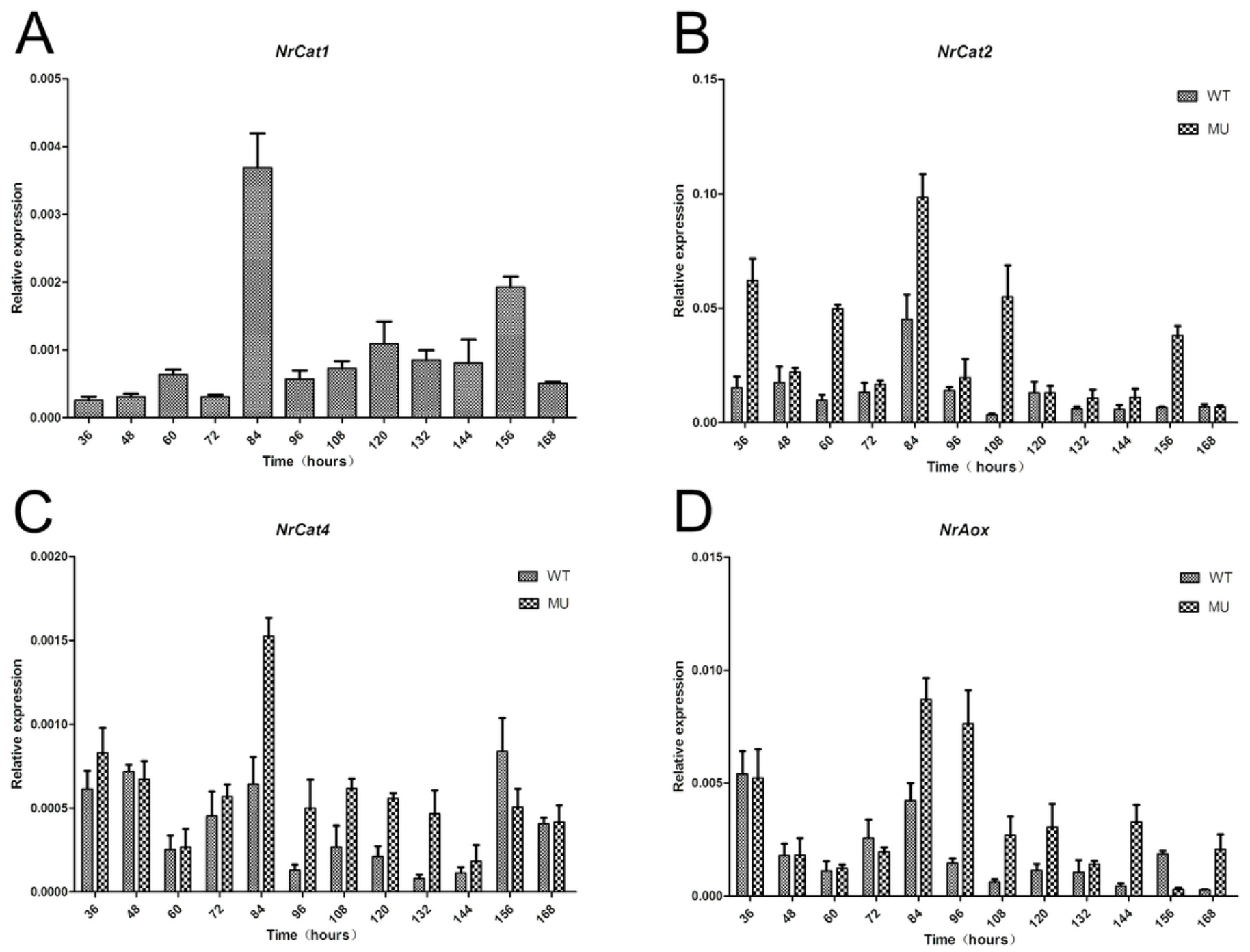

Figure 2

RT-qPCR analysis of NrCat1, NrCat2, NrCat4, and NrAox expression. Total RNA was isolated during different periods of MS development from WT and $\triangle \mathrm{NrCat} 1$ strains. Results are mean relative expression $\pm S D$. 


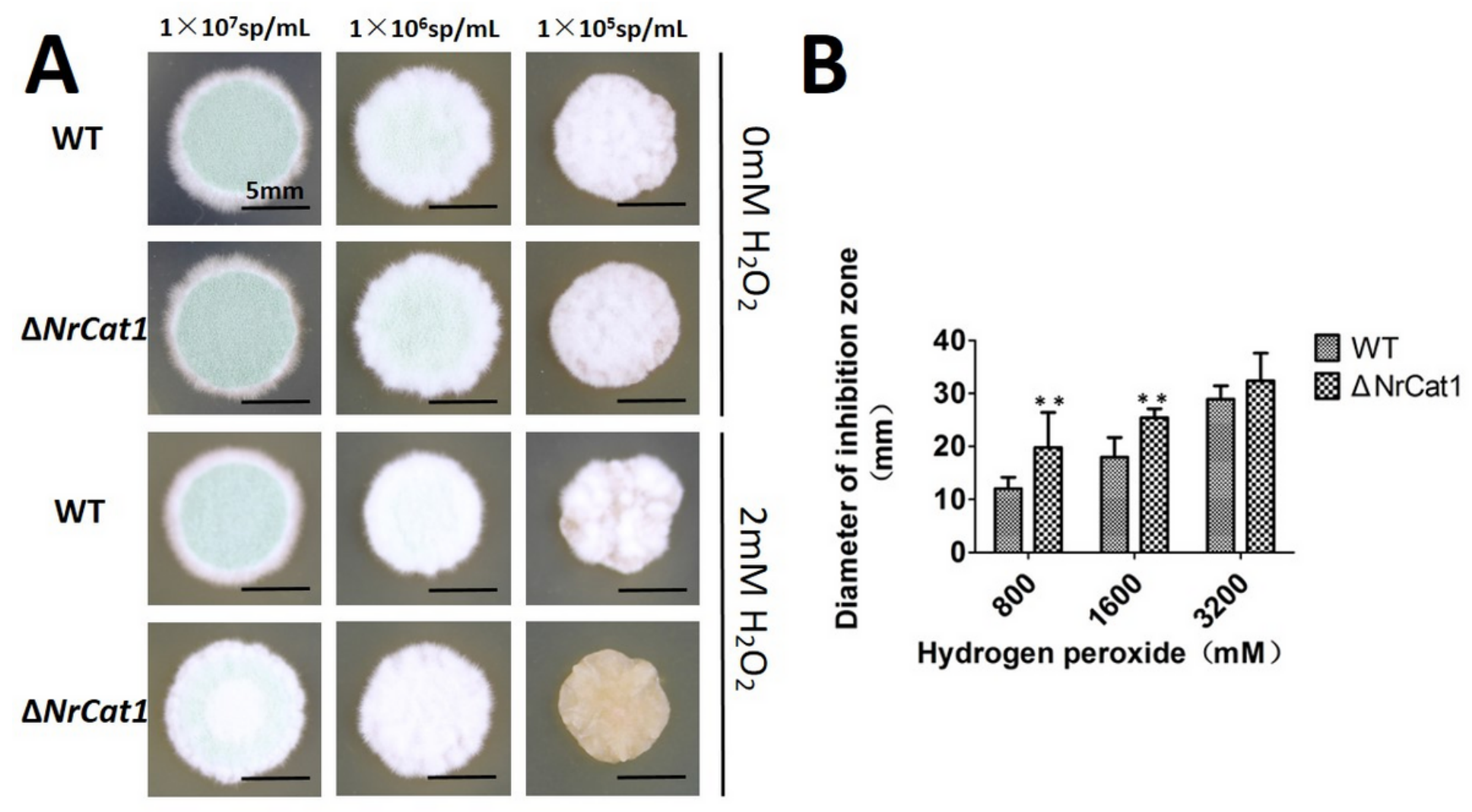

Figure 3

(A)Colony morphology of WT and $\triangle \mathrm{NrCat1}$ strains grown on SMAY plates or SMAY plates supplemented with $2 \mathrm{mM} \mathrm{H} 2 \mathrm{O} 2$ for 7 days. Three concentrations of conidial suspensions $(1 \times 107,1 \times 106$, and $1 \times 105 \mathrm{sp}$ $\mathrm{mL}-1$ ) were pipetted onto the plates. (B) Diameter of $\mathrm{H} 2 \mathrm{O} 2$ inhibition zones at $\mathrm{H} 2 \mathrm{O} 2$ concentrations of 800,1600 and $3200 \mathrm{mM}$. Values are presented as the relative mean \pm SD from five independent assays. Standard error bars indicate variation in measurements. ${ }^{*} \mathrm{P}<0.05$, ${ }^{\star *} \mathrm{P}<0.01$, compared with the wild type strain grown at the same concentration. 

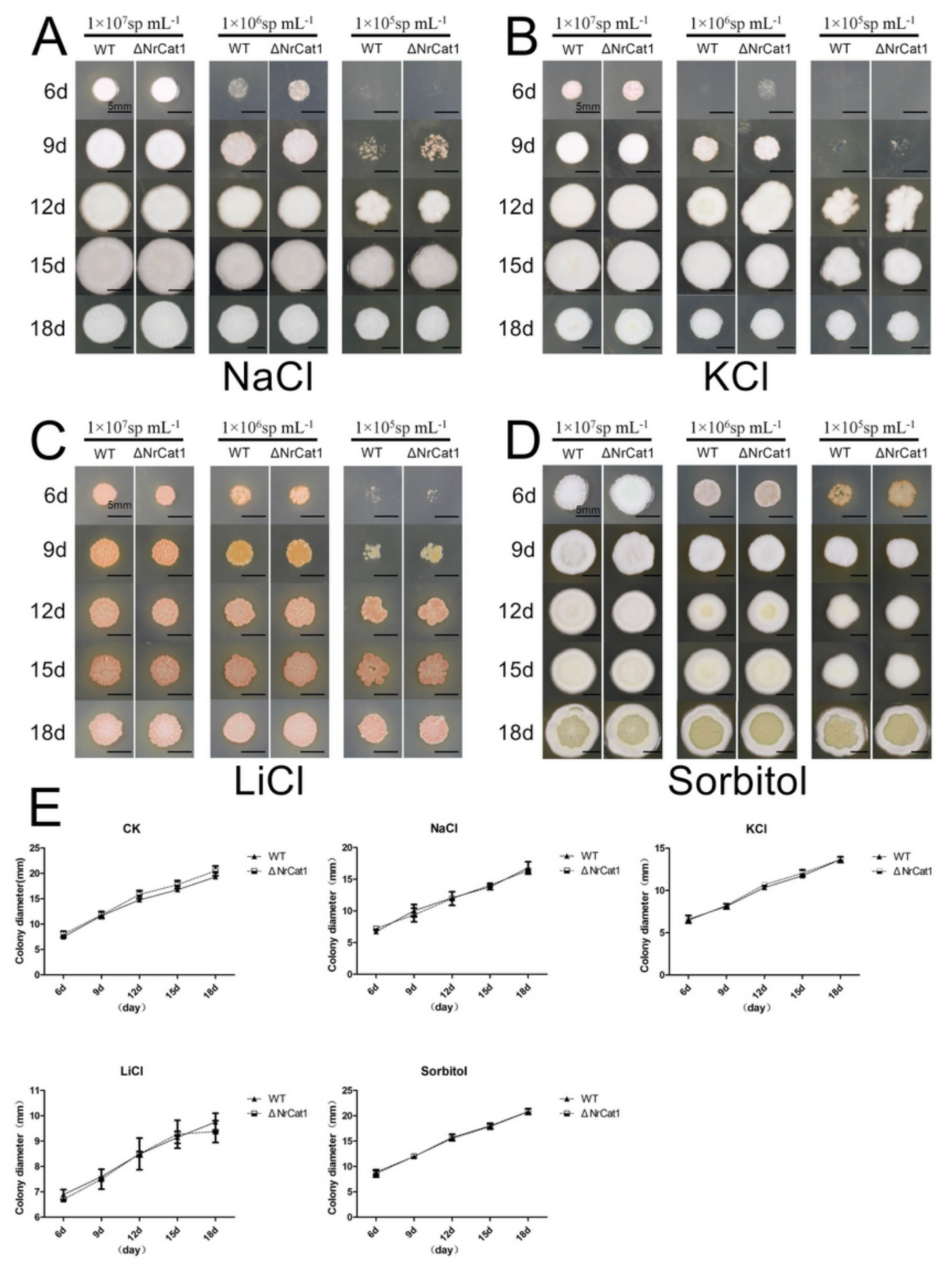

\section{Figure 4}

Colony morphology of WT and $\triangle$ Nrcat1 strains grown on SMAY plates supplemented with (A) $1 \mathrm{M} \mathrm{NaCl}$, (B) $1 \mathrm{M} \mathrm{KCl},(C) 0.04 \mathrm{M} \mathrm{LiCl}$, and (D) $1 \mathrm{M}$ sorbitol from day 6-18. (E) Hyphal extension rates of WT and $\triangle \mathrm{NrCat} 1$ strains grown on SMAY plates and SMAY plates supplemented with $1 \mathrm{M} \mathrm{NaCl}, 1 \mathrm{M} \mathrm{KCl}, 0.04 \mathrm{M} \mathrm{LiCl}$ and $1 \mathrm{M}$ sorbitol. Values are presented as mean relative expression \pm SD from five independent assays. Standard error bars indicate variation in measurements. 


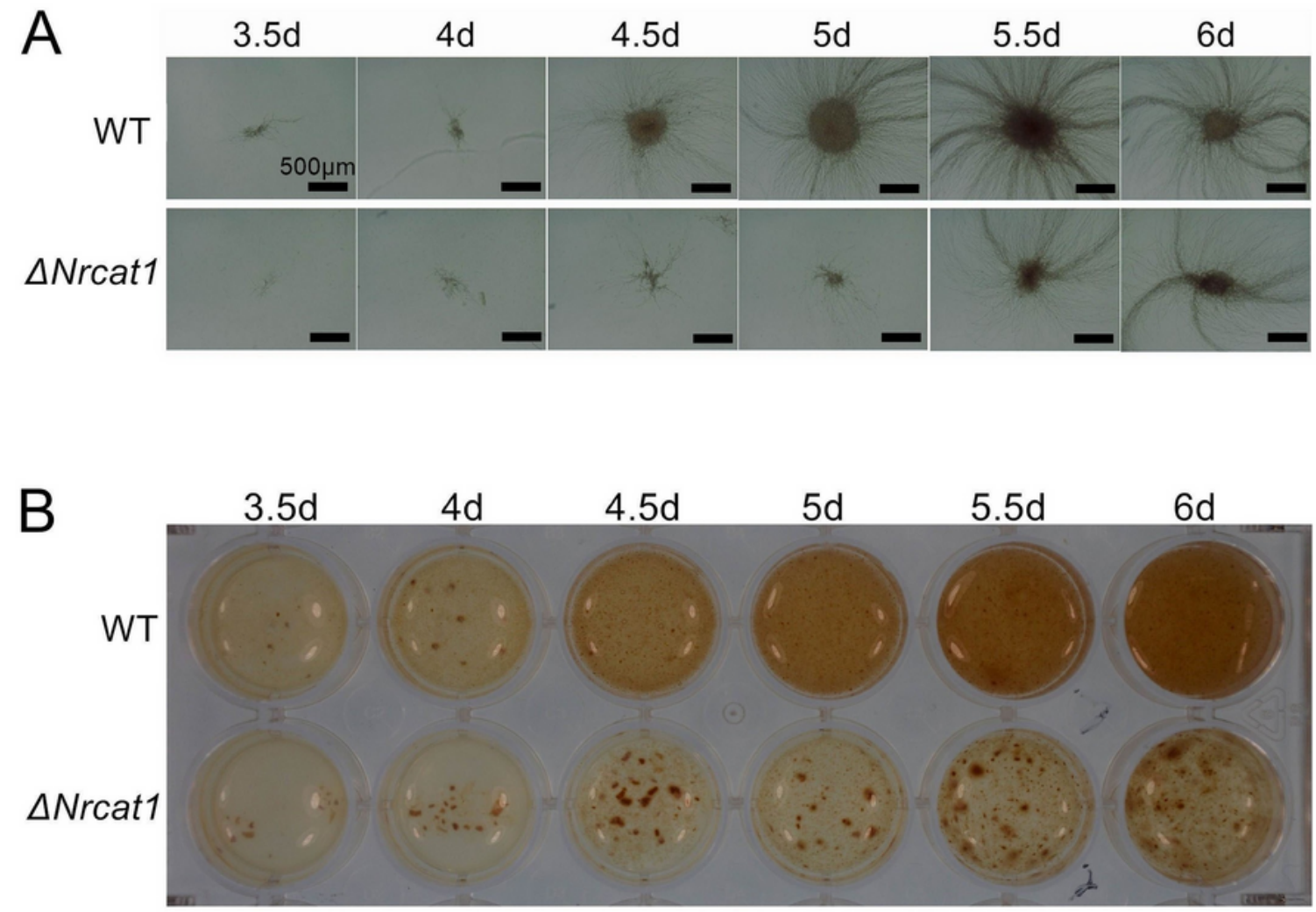

C

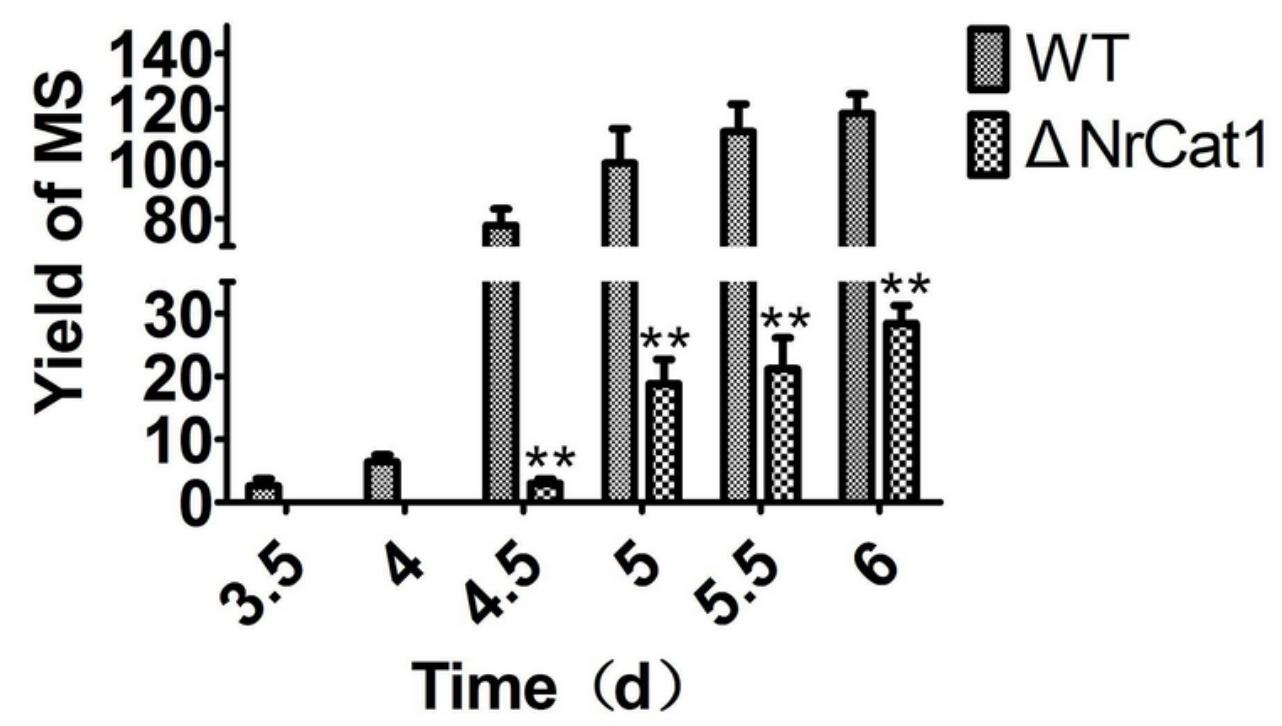

Figure 5

(A) Microscopic images and (B) morphology of WT and $\Delta$ Nrcat1 strains grown in AM media from day 3.5-6. (C) Numbers of MS generated by WT and $\Delta$ Nrcat1 strains from day 3.5-6. Values are presented as relative mean $\pm S D$ from three independent assays. Standard error bars indicate variation in measurements. ${ }^{*} P<0.05,{ }^{*} \mathrm{P}<0.01$, compared with the WT strain at the same time point. 


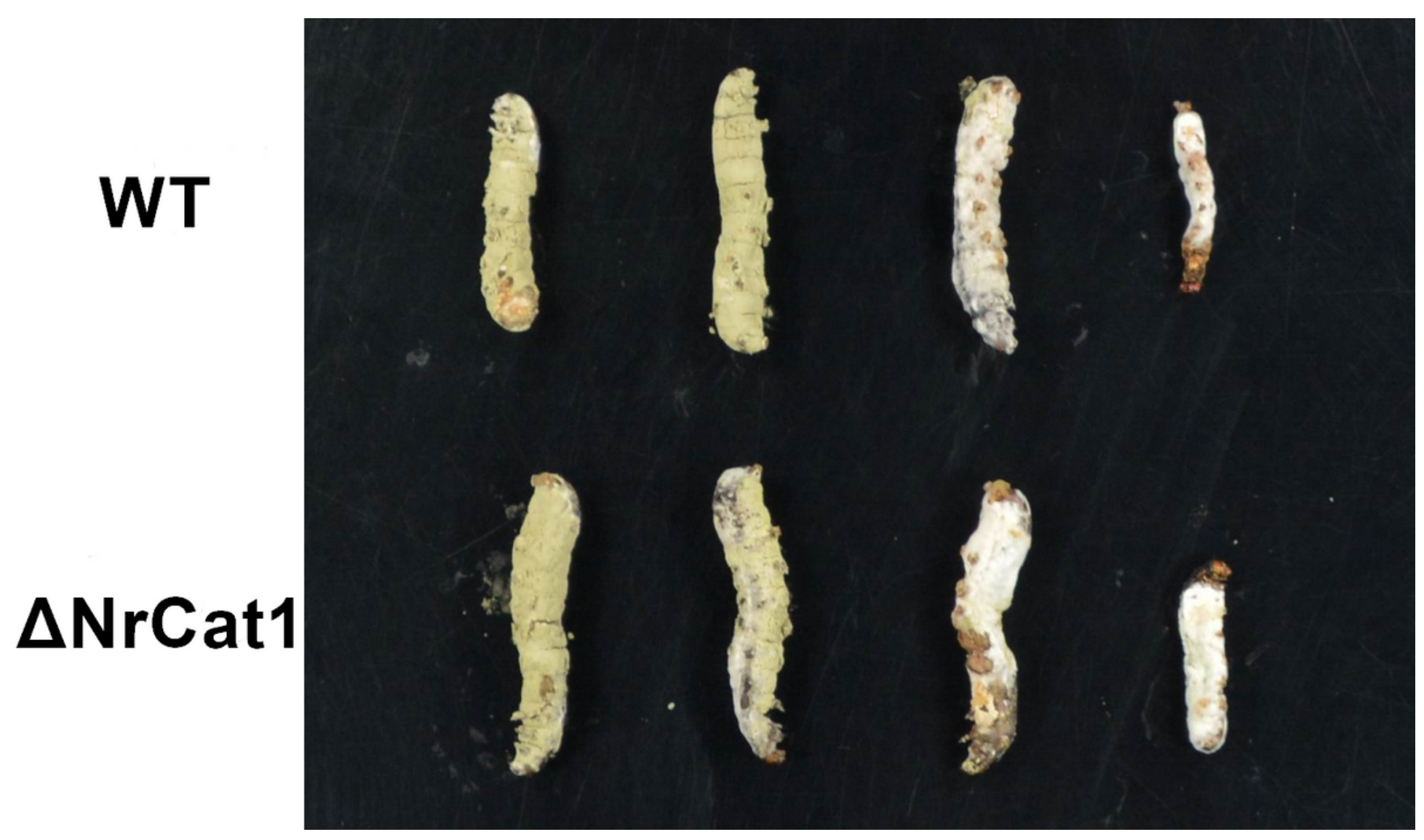

Figure 6

Muscardine cadavers of WT and $\triangle \mathrm{NrCat} 1$ mutant. No significant difference in morphology between WT and $\Delta \mathrm{NrCat} 1$ muscardine cadavers.

\section{Supplementary Files}

This is a list of supplementary files associated with this preprint. Click to download.

- Tables1.docx 